\title{
Objective Measurement of Adherence to Out-Patient Airway Clearance Therapy by High-Frequency Chest Wall Compression in Cystic Fibrosis
}

\author{
Christina L Mikesell DO, Robert R Kempainen MD, Theresa A Laguna MD, \\ Jeremiah S Menk MSc, Andrew R Wey PhD, Philippe R Gaillard PhD, and \\ Warren E Regelmann MD
}

\begin{abstract}
BACKGROUND: Objective measures of adherence to high-frequency chest wall compression (HFCWC), a form of airway clearance therapy for patients with cystic fibrosis, are lacking. We used a novel electronic monitoring device integrated into an HFCWC vest to measure adherence compared with self-reported adherence. We determined factors that influenced adherence and how adherence correlated with baseline pulmonary function and pulmonary exacerbations. METHODS: Data were collected by direct measurement of date, time of day, and duration of HFCWC use to determine the number of daily treatments and daily duration of treatments. Chart review provided prescribed airway clearance therapy treatment and demographic and clinical information. Subject and caregiver report of the daily number of airway clearance therapy treatments was obtained by telephone interviews. Analysis used 2-sample and paired $t$ test, analysis of variance, and linear regression. RESULTS: Average adherence was $69 \%$. Adherence was highest in children $(82 \%$, $P=.02)$ and those receiving assistance with treatment $(82 \%, P<.001)$. Subjects overestimated therapy duration from a mean \pm SD of $127 \pm 169 \%$ by adults to $19.2 \pm 26.3 \%$ by parents or guardians of children. Average adherence decreased with increasing prescribed therapy time $(P=.02)$. Average daily therapy time and adherence had significant positive associations with baseline $\mathrm{FEV}_{1}$ percent of predicted $(P=.02$ and $P=.02$, respectively) and negative associations with pulmonary exacerbations during the pre-study period and at baseline $(P=.044$ and $P=.02$, respectively). CONCLUSIONS: Greater adherence to HFCWC measured directly by a novel recorder was associated with better baseline pulmonary function and fewer exacerbations in the pre-study and baseline period. Adherence decreased with age and prescribed therapy time and increased with therapy assistance. Self-report overestimation is large and thus not an accurate measure of adherence. Key words: adherence; cystic fibrosis; high-frequency chest wall compression; pulmonary function test; pulmonary exacerbation. [Respir Care 2017;62(7):920-927. (C) 2017 Daedalus Enterprises]
\end{abstract}

\section{Introduction}

Approximately $80 \%$ of deaths in patients with cystic fibrosis $(\mathrm{CF})$ stem from respiratory insufficiency (about

\footnotetext{
Dr Mikesell is affiliated with Children's Respiratory and Critical Care Specialists, Minneapolis, Minnesota. Drs Mikesell, Laguna, and Regelmann are affiliated with Pediatric Pulmonology, University of Minnesota Cystic Fibrosis Center and Masonic Children's Hospital, Minneapolis, Minnesota. Dr Kempainen is affiliated with Pulmonary and Critical Care Medicine, Hennepin County Medical Center, and the University of Min-
}

$67 \%$ ) or from complications of lung transplantation (about 13\%). ${ }^{1}$ Impaired mucociliary clearance predisposes patients to recurrent infection, mucus plugging, inflammation, and airway obstruction that ultimately leads to progressive loss of lung function. ${ }^{2}$ A growing number of inhaled and oral

nesota Cystic Fibrosis Center and Hospital, Minneapolis, Minnesota. Mr Menk and Dr Wey are affiliated with the Clinical and Translational Science Institute, University of Minnesota, Minneapolis, Minnesota. Dr Gaillard is affiliated with the Department of Mathematics and Statistics, Auburn University, Auburn, Alabama. 
medications are available to counteract this process. In addition to drug treatments, the Cystic Fibrosis Foundation also recommends regular performance of airway clearance therapy employing one of several techniques. ${ }^{3}$

Advances in treatment have substantially improved survival over the past 3 decades, ${ }^{1}$ but there is evidence that poor adherence prevents patients from fully realizing the benefits of $\mathrm{CF}$ therapies. ${ }^{4-6}$ Relatively little is known about predictors of non-adherence in patients with $\mathrm{CF}$, but duration and complexity of the regimen are likely to be negatively related to adherence. ${ }^{7,8}$ Previous studies also indicate that non-adherence is particularly prevalent during weekends and summer months in school-age patients ${ }^{9}$ as well as among adolescents at any time., ${ }^{4,5}$ Family functioning as well as depression among children and their parents are additional important determinants of adherence. ${ }^{8,10,11}$ Even with the advent of CF transmembrane conductance regulator gene correctors and potentiators, consistent use of airway clearance therapy remains paramount for preserving lung function because these novel medications are unlikely to reverse established bronchiectasis.

Prior studies of airway clearance therapy adherence in subjects with CF commonly employ patient self-report to measure adherence, but this approach consistently yields higher levels of adherence than objective measures. For instance, Daniels et al ${ }^{12}$ compared adherence to prescribed nebulizer therapies in subjects with CF measured by selfreport versus electronic monitoring, and found adherence rates of 80 and $36 \%$, respectively. Published studies that have focused specifically on adherence to airway clearance therapy among subjects with CF have relied primarily on patient, parent, and clinician surveys, with selfreported adherence in the past decade ranging from 14 to 94\%. ${ }^{13-16}$ Actual adherence to airway clearance therapy remains unknown due to the lack of studies with objective

This study was supported in part by grants from the Cystic Fibrosis Foundation and from Hill-Rom, which also provided equipment and assistance in data collection. Dr Laguna has disclosed relationships with the National Institutes of Health, the Cystic Fibrosis Foundation, the Robert Wood Johnson Foundation, the Minnesota Medical Foundation, and Cayston Pharmaceuticals. The other authors have disclosed no conflicts of interest.

Dr Mikesell presented versions of this work at the 2010 and 2011 North American Cystic Fibrosis Conferences, held October 21-23, 2010, in Baltimore, Maryland, and November 3-5, 2011, in Anaheim, California, and at the 2011 American Thoracic Society Conference, held May 13-18, 2011, in Denver, Colorado.

Correspondence: Warren E Regelmann MD, MMC 742, Pediatric Pulmonology, University of Minnesota, Minneapolis, MN 55455. E-mail: rege1001@umn.edu.

DOI: $10.4187 /$ respcare. 05349

\section{QUICK LOOK}

\section{Current knowledge}

A majority of deaths from cystic fibrosis stem from respiratory insufficiency. Advances in treatment have substantially improved survival for this disease over the past 3 decades. Regular performance of airway clearance therapy is recommended for these patients; however, adherence is regarded as poor based largely on subjective data.

\section{What this paper contributes to our knowledge}

We used a novel electronic chronometer and data recorder integrated into a high frequency chest wall compression device to objectively measure daily duration of use. Children with caregivers who assisted with starting therapy had the highest adherence, and adults had the lowest. Neither electronic monitoring nor monthly technician visits affected adherence. Higher baseline $\mathrm{FEV}_{1}$ (percent of predicted) and absence of recent pulmonary exacerbation were associated with better adherence.

electronic monitoring of airway clearance therapy adherence.

Our study compared objectively measured adherence to airway clearance therapy with patient- and parent-reported adherence among children, adolescents, and young adults with CF. We employed a novel electronic monitoring device that recorded the daily timing and duration of patient use of a high-frequency chest wall compression (HFCWC) device. Based on our above review of the literature and our clinical experience, we hypothesized that: (1) objectively measured adherence is lower than self-reported adherence; (2) adherence is lower among adolescents and young adults than children; (3) adherence decreases as prescribed duration of therapy increases; (4) patients who live with a parent or guardian or receive assistance with therapy are more adherent; and (5) patients with recent exacerbations and lower baseline $\mathrm{FEV}_{1}$ are more likely to have lower adherence.

\section{Methods}

\section{Subjects}

Subjects age 6-24 y treated at the University of Minnesota Cystic Fibrosis Center were enrolled. CF was confirmed with a sweat chloride concentration $>60 \mathrm{mmol} / \mathrm{L}$ using Gibson-Cooke pilocarpine iontophoresis. ${ }^{17}$ To be included, subjects had a current prescription for HFCWC for their airway clearance technique, had HFCWC equipment (the Vest System, Hill-Rom, Batesville, Indiana), were 
able to perform valid spirometry, and lived in the region of Minnesota, eastern North and South Dakota, northern Iowa, and western Wisconsin. We excluded those who were in hospice care, did not have $1 \mathrm{y}$ of Minnesota CF center records, or had not been seen for $>1 \mathrm{y}$. Subjects $<13$ y of age were placed into the childhood cohort, those 13-18 y of age were placed into the adolescent cohort, and those $\geq 19$ y of age were placed into the adult cohort.

Subjects who consented for the study but were diagnosed with a pulmonary exacerbation within 2 weeks of enrollment or who had more than one exacerbation in the preceding 6 months were placed in a pulmonary exacerbation group. A generally accepted definition of a pulmonary exacerbation of $\mathrm{CF}$ lung disease based on signs and symptoms that was applicable to children and adults and to our available dataset was not available. ${ }^{18}$ We used a working definition for this study. To be most inclusive, a pulmonary exacerbation was defined as symptoms of a respiratory infection (any one or more of increased cough, increased sputum production, new crackles, new wheeze, new hemoptysis) that resulted in prescribing a new antibiotic and an increase in inhaled medications and airway clearance therapy with or without evidence of a decline in pulmonary function or hospitalization by patient report and chart review. This working definition is most similar to the definition found by Rabin et al ${ }^{19}$ in analysis of the Epidemiologic Study of Cystic Fibrosis data set to correlate with medical caregiver diagnosis and antibiotic treatment of pulmonary exacerbation and that found by Byrnes et $\mathrm{al}^{20}$, in their analysis of the Australasian CF BronchoAlveolar Lavage randomized controlled trial data set, to correlate with family or physician diagnosis of pulmonary exacerbation. ${ }^{21}$

\section{Study Design}

The Vest System model 105 (Hill-Rom) equipped with a novel data recorder was used for the study. All subjects who were using another model of the Vest System were provided with a model 105 device with a data recorder. Patients and their parents or guardians were approached for the study, and consent (or assent with parent/guardian's consent for those $<18$ y old) was obtained by the principal investigator or one of the study staff, not the patient's medical care providers or Hill-Rom. Study personnel did not alter medications, treatment plans, or other CF therapies.

The institutional review board at the University of Minnesota approved this study. After informed consent and enrollment, a questionnaire was filled out by telephone interview performed by study staff. The subjects and the parents/guardians of subjects $<18$ y of age were asked: "How many times a day are you prescribed to do chest therapy?"; "How many minutes is each session prescribed to be?"; "Have you been on antibiotics for a pulmonary exacerbation in the last 2 months?"; "Are you currently living with a parent or guardian?"; and "Does your parent/ guardian assist you with starting your chest therapy?" (only for subjects $<18$ y old). Hill-Rom technicians were required to visit the home to set up the data recorders and download the data at set intervals. Technician visits occurred as close as possible to 30,60 , and $90 \mathrm{~d}$ after the initial home visit to establish $330-d$ observation blocks. At each visit, data were downloaded from the recorders, and if the subject was $\geq 18$ y old, he or she was asked, "How many chest therapy treatments did you do in the last 2 weeks?" If the subject was $<18$ y old, the parent/guardian was asked, "How many chest therapy treatments did your child do in the last 2 weeks?" Each chest therapy treatment reported was assumed to be the prescribed 30-min session. Downloaded data and visit forms were sent electronically to the principal investigator $(\mathrm{CM})$.

\section{HFCWC Recorder Information}

At the Minnesota Cystic Fibrosis Center, patients are routinely prescribed twice daily HFCWC sessions that are $30 \mathrm{~min}$ in duration and consist of 6 different oscillation frequencies of 5-min duration each. HFCWC therapy data were recorded as the total time the system was turned on (in min) during each session, and the total number of sessions. Sessions with pauses $>1 \mathrm{~h}$ were considered 2 separate sessions. All sessions were included unless they lasted $<5 \mathrm{~min}$ or $>60 \mathrm{~min}$, since it was unlikely that a subject was actually participating in a session lasting $>1 \mathrm{~h}$.

A recording device, integrated into each subject's HFCWC device, was turned on at the start of the study. Date; clock time of start, stops, and pauses of high frequency compressions; the compression frequency setting (in $\mathrm{Hz}$ ); and compression pressure intensity setting (1-10) were recorded. If the subject made any key press changes to the settings of frequency, pressure (intensity), and time, this also resulted in a recorded event. The recording devices had a maximum storage capacity of 1,024 events or approximately $60 \mathrm{~d}$. If the maximum number of events were reached, the first event from the beginning of the recording period would be overwritten, and each sequential entry would be overwritten as the number of events beyond the maximum increased. Data were downloaded approximately every $30 \mathrm{~d}$ during a home visit by the technical staff.

The first day of the block in which data were available was used as day 1 . This approach was used for all 3 30-d blocks. If a subject was hospitalized during the study period, these days were removed, because they would otherwise appear as days of no therapy. The data for each 30-d block were then separated into 4 equal quarters. Adherence during the different quarters was compared to assess the influence of an upcoming monitoring visit on adherence. 


\section{Measuring Adherence to Airway Clearance Therapy in CF}

Table 1. Comparative Demographics

\begin{tabular}{|c|c|c|c|}
\hline Attribute & $\begin{array}{l}\text { Study Subjects } \\
\quad(N=85)\end{array}$ & $\begin{array}{l}\text { Patients Meeting Inclusion Criteria but } \\
\text { Not Enrolled at Baseline }(n=125)\end{array}$ & $P$ \\
\hline Age, mean \pm SD y & $15.6 \pm 4.7$ & $17.5 \pm 5.1$ & $.006 *$ \\
\hline \multicolumn{4}{|l|}{ Cohort, $n(\%)$} \\
\hline$<13$ y & $24(28)$ & $23(18)$ & \multirow{3}{*}{$.02 *$} \\
\hline $13-18$ y & $38(45)$ & $45(36)$ & \\
\hline$\geq 19 \mathrm{y}$ & $23(27)$ & $57(46)$ & \\
\hline $\mathrm{BMI}$, mean $\pm \mathrm{SD} \mathrm{kg} / \mathrm{m}^{2}$ & $20.2 \pm 3.2$ & $20.1 \pm 3.0$ & .80 \\
\hline Male sex, $n(\%)$ & $43(51)$ & $64(51)$ & $>.99$ \\
\hline $\mathrm{FEV}_{1}$, mean $\pm \mathrm{SD} \%$ predicted & $97.5 \pm 20.2$ & $87.3 \pm 24.3$ & $.001 \dagger$ \\
\hline$<13$ y & $112.6 \pm 14.9$ & $111.3 \pm 21.8$ & $.81 \dagger$ \\
\hline $13-18$ y & $97.9 \pm 15.2$ & $91.6 \pm 18.5$ & $.09 \dagger$ \\
\hline$\geq 19 \mathrm{y}$ & $81.0 \pm 20.0$ & $74.2 \pm 20.5$ & $.18 \dagger$ \\
\hline \multicolumn{3}{|l|}{ Pancreatic status, $n(\%)$} & \multirow[t]{3}{*}{.81} \\
\hline Insufficient & $78(92)$ & $113(90)$ & \\
\hline Sufficient & $7(8)$ & $12(10)$ & \\
\hline
\end{tabular}

\section{Clinical Data}

Baseline demographics were obtained by chart review. Spirometry met American Thoracic Society/European Respiratory Society validity criteria, ${ }^{22}$ and $\mathrm{FEV}_{1}$ percent of predicted was derived from the National Health and Nutrition Examination Survey III. ${ }^{23}$ Pancreatic insufficiency was considered present if pancreatic enzyme replacement were prescribed. If the HFCWC prescription was not explicitly charted in a visit note, the standard Minnesota Cystic Fibrosis Center prescription of $30 \mathrm{~min}$ twice daily was used, since this is the default prescription that our respiratory therapists provide in their airway clearance therapy instructions to patients.

\section{Statistical Analysis}

Descriptive statistics were computed for demographic attributes (Table 1). Average daily therapy time was calculated directly from the daily measured data averaged over each 30-d interval. Adherence was measured as the measured average daily therapy time as a percentage of the prescribed daily therapy time. This definition was in accord with the World Health Organization initiative on adherence to long-term therapies. ${ }^{24}$ Mean percentage overestimation of performed therapy was calculated as the subject- or parent/guardian-reported duration of airway clearance therapy during these 2 weeks minus the actual duration of airway clearance therapy during these 2 weeks, which was then divided by this actual duration of airway clearance therapy during these 2 weeks and multiplied by 100 . The last 2 weeks of data from each block were used to calculate the mean percent overestimation of performed therapy.

To assess whether adherence decreased over the study period, adherences for blocks 1 and 3 were paired for each subject and analyzed by paired $t$ test. The same analysis was used to evaluate the influence of anticipating technician visits by comparing adherence in quarters 2 and 4 of each block, again analyzed by paired comparison for each subject.

The influences of (1) assistance with therapy and (2) living with a parent for those $<18$ y old were examined using a 2-sample $t$ test. Average adherences and mean percent overestimation were stratified first by prescription and then for age cohort and evaluated by analysis of variance, with follow-up pairwise comparisons using Tukey's standardized range method.

Average daily therapy time as a correlate of baseline $\mathrm{FEV}_{1}$ percent of predicted was assessed by linear regression. The adherence, therapy time, and $\mathrm{FEV}_{1}$ percent of predicted of subjects experiencing a pulmonary exacerbation in the baseline period to those not experiencing a pulmonary exacerbation was compared by 2 -sample $t$ test. All analyses were performed with SAS 9.2 (SAS Institute, Cary, North Carolina) and R software 3.3.2.25

\section{Results}

\section{Comparative Demographics}

Of 210 patients meeting inclusion criteria, 125 remained after exclusion criteria were applied. Of these 125, 104 consented; of these 104, 19 withdrew, leaving 85 studied 


\section{Measuring Adherence to Airway Clearance Therapy in CF}

Table 2. Predictors of Therapy Time, Reported Time, Overestimation, and Adherence

\begin{tabular}{|c|c|c|c|c|}
\hline Group & $\begin{array}{c}\text { Therapy Time } \\
(\text { mean } \pm \text { SD } \mathrm{min} / \mathrm{d})\end{array}$ & $\begin{array}{c}\text { Reported Time } \\
(\text { mean } \pm \text { SD min/d)* }\end{array}$ & $\begin{array}{c}\text { Overestimate } \\
(\text { mean } \pm \text { SD \%) }\end{array}$ & $\begin{array}{c}\text { Adherence } \\
(\text { mean } \pm \mathrm{SD} \%)\end{array}$ \\
\hline \multicolumn{5}{|l|}{ Prescription group $\dagger$} \\
\hline $30 \mathrm{~min} / \mathrm{d}(n=5)$ & $28.7 \pm 15.9$ & $35.2 \pm 14.2$ & $43.8 \pm 67.4$ & $96 \pm 53$ \\
\hline $60 \mathrm{~min} / \mathrm{d}(n=69)$ & $42.1 \pm 18.1$ & $55.9 \pm 16.0$ & $64.6 \pm 116$ & $70 \pm 30$ \\
\hline$>60 \mathrm{~min} / \mathrm{d}(n=11)$ & $46.4 \pm 19.3$ & $69.9 \pm 22.7$ & $64.2 \pm 92.7$ & $50 \pm 21$ \\
\hline \multicolumn{5}{|l|}{ Age group $\$$} \\
\hline$<13$ y $(n=24)$ & $51.8 \pm 9.9$ & $59.7 \pm 7.3$ & $19.2 \pm 26.3$ & $82 \pm 20$ \\
\hline $13-19$ y $(n=38)$ & $42.1 \pm 19.3$ & $56.9 \pm 17.4$ & $52.2 \pm 76.7$ & $69 \pm 31$ \\
\hline$\geq 19$ y $(n=23)$ & $31.0 \pm 17.6$ & $51.9 \pm 25.3$ & $127 \pm 169$ & $56 \pm 39$ \\
\hline \multicolumn{5}{|l|}{ Assistance with therapy§ } \\
\hline Yes $(n=43)$ & $50.8 \pm 14.6$ & $59.8 \pm 12.4$ & $25.6 \pm 37.4$ & $82 \pm 23$ \\
\hline No $(n=26)$ & $36.2 \pm 17.0$ & $54.5 \pm 18.6$ & $81.0 \pm 119$ & $63 \pm 36$ \\
\hline Blank $(n=16)$ & $27.1 \pm 16.5$ & $49.4 \pm 27.5$ & $142 \pm 176$ & $44 \pm 27$ \\
\hline \multicolumn{5}{|c|}{ 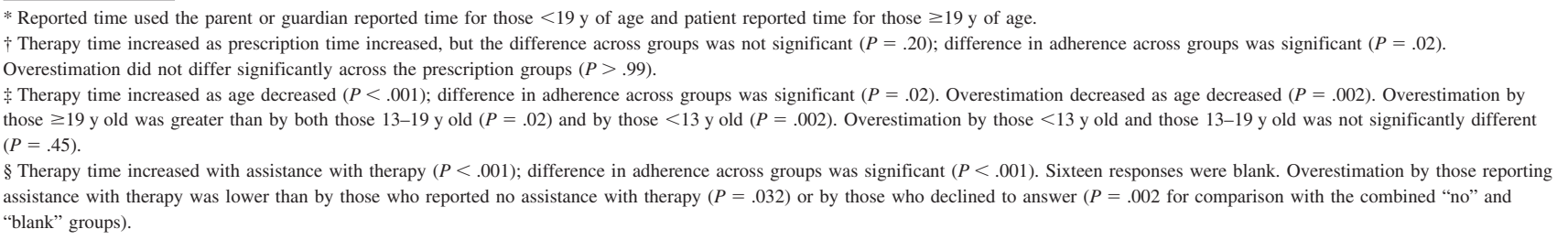 } \\
\hline
\end{tabular}

subjects (Table 1). Patients who met inclusion criteria but were not enrolled consisted of 85 patients who met only inclusion criteria, 21 who did not consent to be studied, and 19 who withdrew between enrollment and the study start $(n=125)$. The studied subjects with $\mathrm{CF}$ had a greater proportion of younger individuals, and the average $\mathrm{FEV}_{1}$ percent of predicted was higher than for those who were not studied. The difference in mean $\mathrm{FEV}_{1}$ percent of predicted between each age group in the studied sample versus those not studied was small and ranged from 1.3 percent of predicted (between the $<13$-y-old age groups) to 6.8 percent of predicted (between the $\geq 19$-y-old age groups).

\section{Objectively Measured Therapy Time, Adherence, Overestimation of Performed Therapy, and Effect of Technician Visits}

Ten subjects had default prescriptions for airway clearance therapy used because prescriptions were not available in the visit charts. Only 2 discrepancies between physician- and subject-reported prescriptions were found. One subject believed they were to do $30 \mathrm{~min}$ less/d and the other $30 \mathrm{~min}$ more.

The average \pm SD therapy time was $41.8 \pm 18.3 \mathrm{~min} / \mathrm{d}$ (range $4.9-87.2 \mathrm{~min} / \mathrm{d}$ ), and the average $\pm \mathrm{SD}$ adherence to airway clearance therapy was $69 \pm 32 \%$ (range $8-175 \%$ ). Adult subjects overestimated the minutes of daily airway clearance therapy they performed in the prior 2 weeks by a mean of $127 \%$ with large variability (SD = $169 \%$ ) (Table 2). Parents or guardians of teens overestimated the amount of daily airway clearance therapy performed by $52.2 \pm 76.7 \%$, and parents or guardians of pre-teens overestimated the amount of daily airway clearance therapy performed by $19.2 \pm 26.3 \%$. Comparisons between the age groups were statistically different comparing the adult versus the teen and the adult versus the pre-teen groups $(P=.02$ and $P=.002$, respectively). Where subject and parent or guardian both reported, overestimation did not differ significantly $(P=.33)$. Parents or guardians who reported that they assisted with starting HFCWC therapy overestimated the daily amount of airway clearance therapy by $25.6 \pm 37.4 \%$, which was significantly less than in those who reported no assistance $(81 \pm 119 \%, P=.032)$ or declined to answer $(P=.002$ for comparison with the combined "no" and "blank" groups).

No monitoring effect was seen. The adherence did not change significantly over the 3 30-d observation blocks with adherence in blocks 1,2 , and 3 being 71, 70, and $69 \%$, respectively ( $\mathrm{SD}=34,33$, and $32 \%$, respectively). Adherence across quarters within each 30-d block did not differ. Average \pm SD adherence per quarter of all 30-d blocks was $70 \pm 32 \%$ during quarter 1, $69 \pm 34 \%$ during quarter 2, $69 \pm 34 \%$ during quarter 3 , and $69 \pm 32 \%$ during quarter 4 . The difference between quarter 2 and quarter 4 adherence, testing the effect of anticipation of a technician visit, was not significant $(P=.92)$. 


\section{Objectively Measured Adherence Was Lower Among Adults Than Children}

Children had the longest average daily therapy time of $51.8 \mathrm{~min} / \mathrm{d}$ and had the highest adherence of $82 \%$ (Table 2 ). The adolescent and adult cohorts performed on average 42.1 and $31.0 \mathrm{~min} / \mathrm{d}$ of therapy time, respectively, and had an adherence of 69 and 56\%, respectively. The difference among these 3 age groups was significant $(P=.02)$. Pairwise comparison by Tukey's test showed a significant difference between the children and adults (difference between means $=26 \%$ and $95 \% \mathrm{CI}=5-47 \%$ ).

\section{Longer Duration of Prescribed Therapy Correlated With Lower Adherence}

Subjects showed a slight but insignificant increase in therapy time as the prescribed time increased (Table 2). Adherence decreased significantly as prescribed therapy time increased.

\section{Subjects Who Received Assistance With Therapy Were More Adherent}

Assistance with starting therapy was associated with significantly higher adherence; those who reported parental/guardian assistance had an $82 \%$ mean adherence compared with $63 \%$ among those who did not (Table 2). Living with one's parents or guardians was not associated with increased adherence $(75 \pm 26 \%$ vs $60 \pm 46 \%$, $P=.25)$.

\section{Lower Baseline Lung Function Correlated With Lower Adherence}

We used $\mathrm{FEV}_{1}$ percent of predicted as a measure of airflow adjusted for growth. This allowed us to compare airflow across our subjects of different ages and sizes. $\mathrm{FEV}_{1}$ percent of predicted at entry into the study was positively correlated with therapy time $(P=.02)$ and adherence $(P=.02)$ observed during the study.

\section{Subjects who experienced pulmonary exacerbation shortly before or within 2 weeks of study enrollment were less adherent}

Comparisons between the pulmonary exacerbation and non-pulmonary exacerbation groups are provided in Table 3. Subjects who received antibiotics for more than one pulmonary exacerbation in the 6 months before or had one pulmonary exacerbation within 2 weeks of study enrollment were significantly less adherent during the study period than those who did not. As expected, mean $\mathrm{FEV}_{1}$ percent of predicted was significantly lower in the pulmo-
Table 3. Comparison of Pulmonary Exacerbation and NonPulmonary Exacerbation Groups

\begin{tabular}{lccc}
\hline \hline \multicolumn{1}{c}{ Attribute } & PE Group & Non-PE Group & $P$ \\
\hline Age, mean \pm SD y & $17.1 \pm 4.1$ & $15.2 \pm 4.9$ & .15 \\
Number & 20 & 65 & \\
Male sex, $n(\%)$ & $10(50)$ & $33(51)$ & .95 \\
FEV $_{1}$, mean \pm SD $\%$ predicted & $88.5 \pm 14.6$ & $100.2 \pm 21.0$ & .02 \\
Therapy time, mean \pm SD min/d & $34.7 \pm 20.3$ & $44.0 \pm 17.1$ & .044 \\
Adherence, mean \pm SD $\%$ & $55 \pm 33$ & $73 \pm 30$ & .02 \\
& & & \\
PE $=$ pulmonary exacerbation & & & \\
\hline
\end{tabular}

nary exacerbation group compared with the non-pulmonary exacerbation group.

\section{Discussion}

We used a new electronic event-monitoring system integrated into an HFCWC device prescribed for airway clearance therapy in subjects with CF to objectively measure adherence. Unlike medications, including those delivered by metered-dose inhalation, airway clearance therapy is time-consuming. At our CF center, the standard prescription is for 230 -min therapy sessions daily when the patient is well and up to 4 times daily when he or she has increased cough, wheeze, sputum production, or shortness of breath. In studies using self-reporting, adherence to airway clearance therapy is between 14 and 94\%.13,14,15,16 As expected from studies using medication event-monitoring systems, we found that parents and subjects overestimated time spent using the HFCWC from about 20 to $127 \%$, respectively, using 2 -week recall. Interestingly, the group of parents or guardians who reported that they assisted with starting HFCWC therapy had a significantly more accurate and precise estimate of the therapy time measured in the prior 2 weeks than those who did not report assisting or did not respond to this question.

Our subjects showed a mean $69 \%$ adherence to airway clearance therapy by the event-monitoring system. This was at the higher end of the range previously documented from self-report. The younger age of our study population and the assistance of parents or caregivers in the therapy may account for this because the maximum adherence was found in those $<13 \mathrm{y}$ of age. This is consistent with studies of subjects with asthma who showed lower adherence using medication event-monitoring systems in adolescents and adults compared with children. ${ }^{26}$ Our study showed that high adherence $(82 \%)$ was associated with the assistance of parents or guardians with the airway clearance therapy of younger subjects. This is consistent with the findings using electronic monitoring of nebulizer adherence of subjects 
with CF. ${ }^{27}$ Strategies to address the drop-off in adherence between childhood and adolescence include behavior-, education-, and technology-based interventions. ${ }^{28}$ Electronic monitoring devices may prove useful for patients interested in tracking their own adherence and also offer objective measures of adherence in intervention trials.

Based on prior studies, we expected to see a Hawthorne effect, with increased adherence as the time of a study technician visit approached. ${ }^{29}$ Interestingly, we found no increase in adherence in the days before such a visit, although the subjects knew when the visit was scheduled and that monitoring their airway clearance therapy was the purpose of the study. One possible explanation is that this effect has generally been shown with relatively simple and short-duration interventions, such as handwashing. Airway clearance therapy with the HFCWC is relatively complex, and each treatment is of long duration, usually $30 \mathrm{~min}$. Such interventions may be less influenced by awareness of once-monthly direct human observation. The electronic monitoring system we used on this HFCWC device performed like the electronic monitoring system of handwashing, ${ }^{29}$ and its use alone simply did not have a large impact on adherence, although the subjects in both of these studies knew that they were being electronically monitored. Alternatively, the subjects and families knew at enrollment that they would be monitored and so may have been at their maximum adherence at the study start, and any additional effect of electronic monitoring or the approaching time of a technician visit was attenuated. However, we found no decrease in adherence over the 3 months of our study period. This is most likely consistent with the subjects being at their routine adherence level during the study period.

Subjects with lower baseline $\mathrm{FEV}_{1}$ percent of predicted and subjects who experienced an antibiotic-treated pulmonary exacerbation had lower adherence during the study period than those who had higher $\mathrm{FEV}_{1}$ percent of predicted and were exacerbation-free. This is consistent with the hypothesis that those who were more adherent had less airway inflammation and obstruction and that the adherence during the study period was similar to adherence before this study period. However, our study does not prove a causal link between reduced adherence to therapy and exacerbation risk. For instance, it is also possible that worsening respiratory status acutely reduced adherence early in the study in the subset of subjects subsequently diagnosed with an exacerbation. The lack of change in adherence in subjects over the 3-month study period makes this possibility less likely.

Our study has several limitations. The studied subjects were self-selected. However, the baseline demographics of those studied and of those who were not were similar when adjusted for age. This suggests that our results were fairly representative of our patients with $\mathrm{CF}$ in each age group. The families knew that they were being monitored. This may have contributed to the higher adherence to airway clearance therapy that we observed. However, we found no effect of anticipation of technician visits on adherence nor difference in adherence during the first month of the study compared with the last month, suggesting that the subjects were in their routine adherence mode. The subjects, parents, or guardians could run the HFCWC device without having it on the subject. However, the continuous clock function recorded the time each day when the device was turned on and off and the duration in each of these modes. Most subjects were turning their HFCWC device on 2-4 times daily, with each "on" period alternating with significant "off" time. This is most consistent with, but does not guarantee, actual use of the HFCWC device on each subject. Previously available monitors simply kept a running total of therapy time. A subject could turn on his or her equipment for multiple hours without actually doing therapy. This "dumping" behavior has been seen in many studies using objective monitoring devices, such as pill and metered-dose inhaler counters. ${ }^{30,31}$ In addition to the date, time, and total duration of each session, the current monitoring device also recorded frequencies, pressures, and pauses used during each session. The subjects were varying frequencies and pausing between frequencies, and many were doing so as prescribed. This pattern is also consistent with use of the device on the subject. Electronic monitoring devices can fail, but we found no failures of devices used in this study over the 3-month observation periods. Finally, adherence to the HFCWC used in our study may not apply to other modes of airway clearance therapy.

A strength of this study was the long observation time in the home setting. This minimized the effect of short-term and clinic-related behavior changes, making accurate measurement of routine adherence more likely. More typical adherence behavior was also more likely to be seen because our study made minimal interventions and required no alterations to the subject's standard CF care.

We conclude from this study that objectively measured adherence to HFCWC airway clearance was lower than self-reported adherence; that adherence was lower among adolescents and young adults than among children; that adherence decreased as prescribed duration of therapy increased; and that subjects who received assistance with starting therapy were more adherent, but monthly, in-home technician visits had no measurable impact on adherence. Subjects with recent exacerbations and lower baseline FEV were more likely to have lower adherence. The electronic measuring device was reliable over at least a 3-month period. A prospective, comparative study of the effect on adherence of active assistance is needed to test the relative usefulness of such interventions to improve adherence, 


\section{Measuring Adherence to Airway Clearance Therapy in CF}

especially among adolescents and adults. The objective data that this novel monitoring device provides are useful in assessing adherence to airway clearance therapy, but further study is needed to determine whether this information can be used to improve adherence.

\section{ACKNOWLEDGMENT}

We thank Lisa Henn PhD for statistical assistance, Ann Hazelwood CRT and Cynthia Williams CCRC for assistance in recruitment, and Marilyn Joseph MD for review of the manuscript.

\section{REFERENCES}

1. Marshall BC. Cystic Fibrosis Foundation Patient Registry: 2013. Annual Data Report. https://www.cff.org/2013_CFF_Patient_Registry_ Annual_Data_Report.pdf. Accessed February 23, 2017.

2. Schechter MS. Airway clearance applications in infants and children. Respir Care 2007;52(10):1382-1390; discussion 1390-1391.

3. Flume PA, Robinson KA, O'Sullivan BP, Finder JD, Vender RL, Willey-Courand DB, et al. Cystic fibrosis pulmonary guidelines: airway clearance therapies. Respir Care 2009;54(4):522-537.

4. Eakin MN, Bilderback A, Boyle MP, Mogayzel PJ, Riekert KA. Longitudinal association between medication adherence and lung health in people with cystic fibrosis. J Cystic Fibrosis 2011;10(4): 258-264.

5. Nasr SZ, Chou W, Villa KF, Chang E, Broder MS. Adherence to dornase $\alpha$ treatment among commercially insured patients with cystic fibrosis. J Med Econ 2013;16(6):801-808.

6. Briesacher BA, Quittner AL, Saiman L, Sacco P, Fouayzi H, Quittell LM. Adherence with tobramycin inhaled solution and health care utilization. BMC Pulm Med 2011;11(1):5.

7. Sawicki GS, Sellers DE, Robinson WM. High treatment burden in adults with cystic fibrosis: challenges to disease self-management. J Cystic Fibrosis 2009;8(2):91-96.

8. Kettler LJ, Sawyer SM, Winefield HR, Greville HW. Determinants of adherence in adults with cystic fibrosis. Thorax 2002;57(5):459464.

9. Ball R, Southern KW, McCormack P, Duff AJ, Brownlee KG, McNamara PS. Adherence to nebulised therapies in adolescents with cystic fibrosis is best on week-days during school term-time. J Cystic Fibrosis 2013;12(5):440-444.

10. Barker DH, Quittner AL. Parental depression and pancreatic enzymes adherence in children with cystic fibrosis. Pediatrics 2016; 137(2):1-9. doi: 10.1542/peds.2015-2296.

11. Smith BA, Modi AC, Quittner AL, Wood BL. Depressive symptoms in children with cystic fibrosis and parents and its effects on adherence to airway clearance. Pediatric Pulmonol 2010;45(8):756-763.

12. Daniels T, Goodacre L, Sutton C, Pollard K, Conway S, Peckham D. Accurate assessment of adherence: self-report and clinician report vs electronic monitoring of nebulizers. Chest 2011;140(2):425-432.

13. Arias Llorente RP, Bousoño García C, Díaz Martín JJ. Treatment compliance in children and adults with cystic fibrosis. J Cystic Fibrosis 2008;7(5):359-367.

14. Myers LB, Horn SA. Adherence to chest physiotherapy in adults with cystic fibrosis. J Health Psychol 2006;11(6):915-926.
15. Modi AC, Cassedy AE, Quittner AL, Accurso F, Sontag M, Koenig JM, Ittenbach RF. Trajectories of adherence to airway clearance therapy for patients with cystic fibrosis. J Pediatr Psychol 2010; 35(9):1028-37.

16. Mcllwaine MP, Alarie N, Davidson GF, Lands LC, Ratjen F, Milner $\mathrm{R}$, et al. Long-term multicentre randomised controlled study of high frequency chest wall oscillation versus positive expiratory pressure mask in cystic fibrosis. Thorax 2013;68(8):746-751.

17. Rosenstein BJ, Cutting GR. The diagnosis of cystic fibrosis: a consensus statement. J Pediatr 1998;132(4):589-595.

18. Flume PA, Mogayzel PJ Jr, Robinson KA, Goss CH, Rosenblatt RL, Kuhn RJ, et al. Cystic fibrosis pulmonary guidelines: treatment of pulmonary exacerbations. American journal of respiratory and critical care medicine 2009;180(9):802-808.

19. Rabin HR, Butler SM, Wohl ME, Geller DE, Colin AA, Schidlow DV, et al. Pulmonary exacerbations in cystic fibrosis. Pediatr Pulmonol 2004;37(5):400-406.

20. Byrnes CA, Vidmar S, Cheney JL, Carlin JB, Armstrong DS, Cooper $\mathrm{PJ}$, et al. Prospective evaluation of respiratory exacerbations in children with cystic fibrosis from newborn screening to 5 years of age. Thorax 2013;68(7):643-651.

21. Waters V, Ratjen F. Pulmonary exacerbations in children with cystic fibrosis. Ann Am Thorac Soc 2015;12(Suppl 2):S200-S206.

22. Miller MR, Hankinson J, Brusasco V, Burgos F, Casaburi R, Coates A, et al. Standardisation of spirometry. Eur Respir J 2005;26(2):319338 .

23. Hankinson JL, Odencrantz JR, Fedan KB. Spirometric reference values from a sample of the general US population. Am J Respir Crit Care Med 1999;159(1):179-87.

24. Sabaté E. Adherence to long-term therapies: evidence for action. World Health Organization; 2003. http://apps.who.int/iris/bitstream/ 10665/42682/1/9241545992.pdf. Accessed February 23, 2017.

25. R Core Team. R: A language and environment for statistical computing. R Foundation for Statistical Computing, Vienna, Austria. 2016. https://www.R-project.org. Accessed February 23, 2017.

26. Bender B, Wamboldt FS, O'Connor SL, Rand C, Szefler S, Milgrom $\mathrm{H}$, Wamboldt MZ. Measurement of children's asthma medication adherence by self report, mother report, canister weight, and Doser CT. Ann Allergy Asthma Immunol 2000;85(5):416-421.

27. Modi AC, Marciel KK, Slater SK, Drotar D, Quittner AL. The influence of parental supervision on medical adherence in adolescents with cystic fibrosis: developmental shifts from pre to late adolescence. Child Health Care 2008;37(1):78-92.

28. Bishay LC, Sawicki GS. Strategies to optimize treatment adherence in adolescent patients with cystic fibrosis. Adolesc Health Med Ther 2016;7:117-124.

29. Hagel S, Reischke J, Kesselmeier M, Winning J, Gastmeier P, Brunkhorst FM, et al. Quantifying the Hawthorne effect in hand hygiene compliance through comparing direct observation with automated hand hygiene monitoring. Infect Control Hosp Epidemiol 2015;36(8):957-962.

30. DiMatteo MR, Giordani PJ, Lepper HS, Croghan TW. Patient adherence and medical treatment outcomes: a meta-analysis. Med Care 2002;40(9):794-811.

31. Burkhart PV, Dunbar-Jacob JM, Rohay JM. Accuracy of children's selfreported adherence to treatment. J Nurs Scholarsh 2001;33(1):27-32. 